\title{
2011 In Vitro Biology Meeting June 4-8, Raleigh, North Carolina
}

\author{
Late Submission Abstract
}

Published online: 6 October 2011

(C) The Society for In Vitro Biology 2011

P-3028 Induction and Multiplication of Embryogenic Callus of Coffea arabica L. Elite Genotypes

Carlos H. S. Carvalho, Embrapa Coffee, Ana Carolina R. S. Paiva, Elizane Q. Silva, Aline A. Custódio, Jaqueline Pala, and Vanessa R. Paulino

\section{EMBRYOGENESIS/MICROPROPAGATION/ REGENERATION \\ P-3028}

Induction and Multiplication of Embryogenic Callus of Coffea arabica L. Elite Genotypes. CARLOS H. S. CARVALHO $^{1}$, Ana Carolina R. S. Paiva ${ }^{2}$, Elizane Q. Silva ${ }^{2}$, Aline A. Custódio ${ }^{2}$, Jaqueline $\mathrm{Pala}^{2}$, and Vanessa R. Paulino $^{2}$. ${ }^{1}$ Embrapa Coffee, PqEB s/no, Brasília, DF, BRAZIL, CEP 70770-901 and ${ }^{2}$ Procafé Foundation, Varginha, MG, BRAZIL. Email: carlos.carvalho@embrapa.br

Somatic embryogenesis is the method of choice for industrial propagation of heterozygous coffee plants. This technique applied to genetic improvement of arabica coffee allows for the selection of mother plants in only 10 years. This work reports the optimization of a protocol for induction and proliferation of embryogenic callus of 17 elite Coffea arabica L. plants with leaf miner and rust resistance selected in Brazil. This protocol has now been used for large-scale propagation of coffee plants. It was found that embryogenic callus induction was much higher when the leaves were collected during fruit development, from January to June $(81.50 \%)$ than from July to December $(9.35 \%)$ and that the second and third pairs produced more embryogenic callus than the 1st pair. The results also indicated that explant subculture is not necessary during the second phase of callus induction (4-5 months). The percentage of explants with embryogenic callus depended on the genotype and also on the general state of the plant. In general, healthy plants with high vigor produced the higher percentage of explants with embryogenic callus, $60-80 \%$. In average, $34 \%$ of the explants of the 17 genotypes plated in a 2-year assay produced embryogenic callus. Callus proliferation was much faster in liquid than in gelled medium with an increase of callus mass of 6.7 times in liquid medium and only 3.0 times in the gelled. Callus growth rate in liquid medium ranged from 53.3 to $1051.1 \mathrm{mg}$, with an overall average of $328.7 \mathrm{mg}$, for every 15 days. Callus growth was highly genotype dependent, but varied among callus lineage within the same genotype suggesting that callus selection can be used to increase multiplication rate.

Index

Carvalho, Carlos H. S. P-3028

Custódio, Aline A. P-3028

Paiva, Ana Carolina R. S. P-3028

Pala, Jaqueline P-3028

Paulino, Vanessa R. P-3028

Silva, Elizane Q. P-3028 